\title{
Cognitive-Behavioral Treatment of Men Who Batter: The Short-Term Effects of Group Therapy ${ }^{1}$
}

\author{
Daniel G. Saunders ${ }^{2}$ and Darald Hanusa ${ }^{3}$
}

A cognitive-behavioral approach for the treatment of wife abuse was evaluated using a pre-post design and multiple outcome measures. The treatment approach consisted of assertiveness training, relaxation training, and cognitive restructuring. Treatment also focused on increasing the client's acceptance of sex-role changes. Data were available on 92 men who completed 12 sessions of a skills group and eight sessions of a supplemental process group. There were significant changes in the desired direction in anger level, jealousy, depression, and attitudes about women's roles. These changes were maintained after adjusting scores for social desirability response bias. The importance of adjusting scores for response bias or obtaining spouse's reports of the man's behavior is discussed.

KEY WORDS: wife abuse; treatment evaluation; cognitive-behavioral; group therapy.

\section{INTRODUCTION}

The physical abuse of women by their husbands or boyfriends has been revealed as a major social problem. A representative survey of the U.S. population showed that at least one third of all wives are subjected to

\footnotetext{
'The authors are grateful to Nancy Bein, Leah Steinberg, Doris Stormoen, Linda Szczepkowski, and Michelle Wilderman for coding the data and rating the MTFC scale. This study was supported in part by NIMH Grants MH-15161-06 and MH-17139-01 while the first author was a postdoctoral research fellow.

${ }^{2}$ Family Service, Madison, Wisconsin 53703, and Department of Psychiatry, University of Wisconsin School of Medicine, Madison, Wisconsin 53792.

${ }^{3}$ Family Service, Madison, Wisconsin 53703.
} 
some form of physical abuse during their marriage. At least $5 \%$ of these women receive severe abuse every year (Straus et al., 1980). The actual rates of abuse are undoubtedly much higher due to underreporting, and these figures do not include the abuse which sometimes occurs after divorce or separation (Kenny, 1981). Physical abuse is also a serious problem for dating couples (Cate et al., 1982; Laner, 1983; Makepeace, 1981). Such abuse appears to lead to severe depression, post-traumatic stress, and substance abuse (Herman, 1986; Stark et al., 1979; Walker, 1984), and its effects go beyond the couple. It causes psychological trauma to any children in the home and increases the likelihood that these children will be violent as adults (Hilberman and Munson, 1977; Levine, 1975; Moore, 1975; Straus et al., 1980; Westra and Martin, 1981).

Intervention has primarily focused on crisis services for battered women and their children, but increasingly intervention programs have focused on the men and on the couple's relationship (Roberts, 1982; PirogGood and Stets-Kealey, 1985). Although crisis services for the women need to be greatly expanded to meet their needs, the importance of invervention with their partners is being recognized. Many couples remain together after the women seek shelter services (Lesser, 1981; Snyder and Scheer, 1981) and, if divorce occurs, the men sometimes find other partners to abuse (Pagelow, 1981).

Treatment for men who batter has used individual, couple, and group formats and a variety of methods. These methods include cognitive restructuring (Bedrosian, 1982), family systems (Bedrosian, 1982; Cook and Frantz-Cook, 1984; Geller and Walsh, 1977; Geller and Wasserstrom, 1984), and self-help (Goffman, 1980). Methods have also been combined, for example: (a) insight and problem-solving therapy (Adams and McCormick, 1982; Brisson, 1982), (b) cognitive methods and joint problem-solving (Margolin, 1979), (c) operant and classical conditioning techniques with communication training (Saunders, 1977), and (d) cognitive and behavioral methods (Deschner, 1984; Edleson et al., 1985; Ganley, 1981; Neidig and Friedman, 1984; Saunders, 1982).

By its nature the self-help approach is often tied to a group format, but the other treatment approaches can be found in any of the following formats: men alone, men in groups, couples, and couples in groups. For example, cognitive-behavioral methods have been applied in both men's groups (Edleson et al., 1986; Saunders, 1984) and couples' groups (Deschner, 1984; Neidig and Friedman, 1984).

A cognitive-behavioral approach was chosen for this study because its components have been shown to be effective in the treatment of dysfunctional anger and aggression. A cognitive-behavioral approach typically combines assertiveness training, relaxation training, and cognitive restructuring. 
The combination of relaxation training and cognitive restructuring has been found to be especially effective in lowering anger arousal (Novaco, 1976). Evidence that assertiveness can successfully be learned as a substitute for aggression is based mainly on nonexperimental case studies (Foy et al., 1975; Howells, 1976; Rimm, 1977), but some experimental evidence also exists (Allen, 1978). One study of nine aggressive individuals showed positive results from a combination of skills training, relaxation training, and cognitive restructuring (Frederiksen and Rainwater, 1981).

A major goal of our treatment approach is to impart skills which are incompatible with aggression, but an equally important goal is the development of attitudes which are associated with nonviolent marriages, attitudes which support sex-role equality, and egalitarian decision-making. This goal is important because of the association between wife abuse and patriarchal norms and family structure (Straus et al., 1980, Yllo, 1983). Both cognitive restructuring and assertiveness training are used to achieve this goal. Cognitive restructuring exercises are used to increase the acceptance of sex-role equality and to decrease possessiveness and jealousy in the marital relationship. Some assertiveness skills, for example empathy and the clear expression of feelings and needs, often set the stage for egalitarian decisionmaking.

In addition to attitudes about sex roles, there is evidence that men who batter suffer from low self-esteem and depression (Neidig et al., 1986; Rouse, 1984). There is an increasing recognition of the role played by feelings of helplessness and low self-efficacy in producing aggression of all types (Novaco, 1977; Turner et al., 1981). Men who batter appear to be hypersensitive to criticism and subsequently become aggressive because of feelings of vulnerability. Therefore, skills training could also be expected to increase feelings of self-efficacy and lessen their symptoms of depression (Ball, 1977; Coleman, 1980; Saunders, 1984).

Despite the growing number of published reports of treatment methods, the evaluation of these methods is generally lacking. Many reports include case descriptions, but only a few of these reports use standardized measures.

Edleson and his associates (Edleson et al., 1985) used a multiple baseline design to evaluate the success of a cognitive-behavioral approach with nine men. Seven of the men reported cessation of violence over a 13-month follow-up period. A major weakness of the study was its reliance on the men's rather than the women's reports, because men generally report less violence (Edleson and Brygger, 1986; Jouriles and O'Leary, 1985).

Several larger studies of cognitive-behavioral methods have relied on the partners' reports of violence at follow-up. Three studies at the Minneapolis Domestic Abuse Prolect combined cognitive-behavioral treatment of men in groups with self-help, insight, or couples groups. In the first 
study, combining skills-training and self-help approaches, $67 \%$ of the women whose partners completed treatment were free of violence at 6 months follow-up; this compared with $54 \%$ of those whose partners dropped out of treatment (Lund et al., 1982). The men reported that they became less traditional in their views of women's roles and that they improved their level of affective communication. They did not change in their self-reports of the need to control others.

In two other studies which combined cognitive-behavioral and traditional group psychotherapy, $68 \%$ of the women reported no violence during the follow-up period in one study and 59\% in another (Edleson and Grusznski, 1986). The outcome of the latter study may have been affected by the higher proportion of men with mental health and chemical dependency problems. The two studies that had a comparison group of noncompleters showed that the men in treatment could lower the level of their physical abuse but not their verbal abuse. The methods of the above studies suffer because a high proportion of the women could not be contacted at follow-up and, of those contacted, no attempt was made to control for those who were no longer in the relationship.

Three studies report on the use of cognitive-behavioral methods in a couples' group format. Deschner (1984) reports that after 10 sessions, 12 men reported on the Taylor-Johnson Temperament Analysis that they were less nervous, depressed, inhibited, and submissive. The scores on "hostility" and five other subscales did not change significantly. Over the course of treatment the violence of 47 men decreased by half, but this was not a statistically significant change.

The treatment described by Myers (1984) lasted for a year, the first six months emphasizing psychotherapy and skills training and the last six months emphasizing support. After six months, 24 of the men showed lower scores on the depression and psychopathic deviate scales of the MMPI and improvement on measures of affective communication and problem-solving in marriage.

Neidig (n.d) also reports an evaluation of a highly structured couples group lasting for 10 sessions. Forty of the men who completed treatment showed significant improvement on two of the four subscales of the Dyadic Adjustment Scale (cohesion and consensus) and more of an internal locus of control on the Nowicki-Strickland Locus of Control Scale.

Two other large-scale studies have been attempted but they have serious methodological drawbacks. They both aggregated data across highly dissimilar types of programs and they relied on retrospective accounts after treatment or estimates of recidivism by program directors (Pirog-Good and Stets, in press; Stacey and Shupe, 1984).

The purpose of the present study was to assess a variety of attitude and psychological changes reported by clients which occurred over the course of 
structured, cognitive-behavioral treatment for woman abuse. It has some improvements over previous studies because it used a relatively large sample size, relevant variables not used before, and correction of the measures for social desirability response bias. The treatment was applied in a small group format. A detailed description of the content of the group sessions is presented elsewhere (Saunders, 1984), with a general description presented below.

\section{METHOD}

\section{Subjects}

Ninety-two clients who completed treatment in 1 of 13 groups were the subjects of the study. They were referred by their partners or by social service or criminal justice agencies. Since treatment groups began in 1978, there have been 30 groups. The package of outcome measures reported in this study was used with the last 18 groups. Five of these groups were excluded from the analysis for the following reasons: either the leaders were inexperienced, there were incomplete data for over $30 \%$ of the cases, or the noncompletion rate exceeded $40 \%$. Groups with a high noncompletion rate were excluded because they could artificially inflate the success rate, as they would have the most highly educated and highly motivated clients.

The violence of most of the subjects was more severe than slapping and shoving. Using a modified Conflict Tactics Scale (Straus, 1979) in the intake interview, over half of them admitted to hitting their partners with their fists or kicking them; many admitted choking or strangling their partners.

The men had the following characteristics: mean age of 31.4 (SD = $7.76)$, mean years of education of $13.2(\mathrm{SD}=2.6)$, mean income of those working was $\$ 20,638$ (SD $=\$ 9099)$. Fourteen percent of the men were unemployed; $62 \%$ were blue collar workers, $25 \%$ were white collar workers, and $13 \%$ were students. Eighty-eight percent of the men were Caucasian, $8.7 \%$ black, $2.2 \%$ hispanic, and $1 \%$ Native American.

The average length of the relationship was 7.0 years $(S D=6.1)$. About $42 \%$ of the men were married, $33 \%$ single, and $23 \%$ separated or divorced at the time of intake.

There were 21 men who started but did not complete treatment; they differed in several ways from those who did. They were significantly younger $(M=28.5$; $\mathrm{SD}=5.4)$, had lower incomes, were more likely to be unemployed $(44 \%)$, were in shorter-term relationships $(M=4.5$ years; $\mathrm{SD}=2.6)$, and more likely to be single $(48 \%)$, than divorced/separated $(26 \%)$ or married $(26 \%)$. At the point of intake, the completers and noncompleters differed on only one of the six outcome variables. Those who 
did not complete treatment tended to report less anger in situations involving friends and coworkers $(M=6.8$ vs $14.8 ; t=-1.93 ; p<.03)$.

During individual assessment interviews, men are screened out of the groups for problems of illiteracy, severe mental disorders, or severe alcohol abuse. Men with these problems are often seen on an individual basis or referred elsewhere for treatment. Adequate reading and writing skills are needed for the group because of the homework requiring these skihls.

\section{Procedure}

Following 2 to $4 \mathrm{hr}$ of individual assessment, the men participated in 12 structured, skills group sessions and 8 process group sessions. Each of the skills-training groups was led by two males or a male-female therapy team. Each group had at least one leader with at least a master's degree in social work or counseling and with experience in conducting structured skills groups.

Beginning the fourth week of the skills-training group the men also began attending a "process" group. Thus, for an 8-week period they attended two groups weekly. In the second group, members practiced skills, integrated them into their daily lives, and gave and received support for changing attitudes and behavior. These process groups were led by former skills group members, with professional consultation available before, during and after the group.

The major components of the skills group were: (a) assertiveness training, (b) relaxation training, (c) cognitive restructuring, and (d) consciousnessraising about the roots of violence.

Session One of the skills group covered an overview of sessions, learning about the group from a former member, and an introduction to assertiveness training and relaxation training. Assertiveness training was taught in Sessions Two through Eight with a review in Session Nine. The skills were taught in the following sequence: (a) coping with criticism, (b) making assertive requests, (c) saying "no" assertively, (d) empathizing with other's feelings, and (e) expressing feelings.

Progressive relaxation training was taught in the first few sessions. The number of muscle groups taught in the relaxation training decreased over the course of the sessions, as described by Bernstein and Borkevec (1973). From Session Seven through Eleven a desensitization hierarchy and coping imagery were combined with the relaxation exercises.

Cognitive restructuring was used in Sessions Seven through Twelve. Anger-producing self-talk was illustrated by the leaders, and the men were taught how to change their own negative talk into coping statements. A 
weekly anger diary helped remind the men of particular anger situations including their self-talk.

Consciousness-raising exercises were used at several points over the 12 weeks and in particular in the last two sessions. These exercises helped the men become more aware of the link between their violence, their victimization in their families of origin, and their male socialization to be aggressive, competitive, and possessive.

\section{Measures}

\section{Anger Scale}

A modified version of the Novaco Anger Scale was used to measure the amount of anger the men perceived they would have in a variety of situations. Novaco's (1976) 80-item scale showed an internal reliability coefficient of 0.96 (alpha) and test-retest reliability of $r=0.83$. The scale has obvious content validity. It showed significant changes following cognitive treatment and cognitive plus relaxation treatment in Novaco's experiment. A five point scale is used by respondents to indicate the extent to which each situation would make them angry, from "very little anger" to "very much anger." Because the goal of treatment is to regulate anger rather than eliminate it, oniy the two highest levels of anger were analyzed. Low to moderate levels of anger were considered acceptable and in many cases desirable.

Since none of the items pertained to marital interaction, 20 of the interpersonal items of the scale had the word "person" changed to "partner." Ten items were also added which used some of the same situations as the "partner" items, but the word partner was changed to "friend," "coworker," or "boss." Thus, levels of anger in marital situations could be compared with anger levels in other situations. Using the sample of this study, the Anger Toward Partner situations had an internal reliability coefficient of 0.89 (alpha) and the Anger Toward Work/Friend situations had an internal reliability coefficient of 0.81 (alpha).

\section{Male Threat from Female Competence (MTFC)}

This variable was measured with a projective sentence completion task developed by Pleck (1982). Three sentence completion stems aimed at measuring the variable were embedded in a longer sentence completion task (e.g., "When Betsy knew more about something than Andy did, he ..."). 
Trained raters, either graduate students or professional counselors, rated the responses as either threatened, neutral, or positive. Interrater agreement was $93 \%$ for ratings of responses as either threatened, positive, or neutral. The first author rated the $7 \%$ of the responses over which there was disagreement.

Construct validity was established in the original study by showing that men scoring as highly threatened on the scale and placed in a competititve task situation with their partners wanted to avoid such competition in the future. In addition, they elevated their level of task activity. Other fantasy and sex role measures were not related to performance.

\section{Beck Depression Inventory}

This inventory consists of 21 items, each item listing a range of severity of symptomatology. These symptoms cover somatic complaints, guilt, pessimism, and indecisiveness. The reliability of the instrument is adequate; the uncorrected split-half correlation was 0.86 (Beck et al., 1961). Validation was demonstrated in two studies showing significant correlations in the expected direction between the inventory and ratings of patient's depression.

\section{Attitudes toward Women Scale (AWS)}

The 15-item version of this scale was used (Spence et al., 1975). Its internal reliability (alpha) was 0.89 with a sample of college students. It has shown construct validity by the way it differentiates males and females and older and younger persons in expected directions; the way high scoring, profeminists react to competent women differently than others; and the association between valuing sex-stereotyped traits on the Personal Attribute Questionnaire and conservatism on the AWS (Spence and Helmreich, 1978). The response format is a four point Likert scale from "strongly agree" to "strongly disagree."

\section{Jealousy Scale}

Romantic jealousy was measured using a 6-item scale developed by White (1977). He showed that the scale had high internal reliability and was uncorrelated with social desirability response bias. The scale showed construct validity because it correlated with several variables as predicted, such as the degree of dependency on the relationship. 


\section{Marlowe-Crowne Social Desirability Scale}

This scale was used as a measure of response bias to remove a common source of invalidity from the other measures. It measures the extent to which subjects attempt to look good in their responses. A ten item Likert version of the scale was used (Greenwald and Satow, 1970). It correlates highly $(r=0.73$ ) with the original 33 item, true-false version (Crowne and Marlowe, 1964). The scale is generally uncorrelated with psychopathology, but it correlates significantly in expected directions with the three validity scales of the MMPI (Crowne and Marlowe, 1964).

All of the measures in the study were adjusted for social desirability response bias using the following steps:

(1) Simple regression was used in order to find the unstandardized regression coefficient in predicting the unadjusted scale from the MarloweCrowne Scale. This coefficient is the correction factor. The regression formula is as follows: $Y=\mathrm{A}+(X)(b)$; where $Y$ is the measure to be adjusted, $A$ is the constant, $X$ is the Marlowe-Crowne Scale, and $b$ is the unstandardized regression coefficient.

(2) Adjusted scores were then created with the following formula: $Y^{\prime}=\mathrm{Y}-(X)(b)$; where $Y^{\prime}$ is the adjusted score, $Y$ is the unadjusted score, $X$ is the Marlowe-Crowne score, and $b$ is the unstandardized regression coefficient.

(3) A check was performed on the above steps by correlating the Marlowe-Crowne scale with the adjusted measures. All of the correlations were zero, indicating that the bias had been removed from the measures.

\section{Correlations among the Outcome Measures}

In order to further evaluate the construct validity of the outcome measures and to determine the degree of redundancy among these measures, correlations were performed among them. Consistent with Novaco's (1977) formulation regarding the positive relationship between depression and proneness to anger, among both pretest and posttest scores, there was a relationship between scoring high on depression and scoring high on both scales measuring anger $(r=0.25$ and 0.32 ). The two anger scales correlated with each other as expected $(r=0.34$ and 0.47$)$. The depression inventory correlated positively and significantly with the jealously scale $(r=$ 0.36). Both the depression inventory and the jealousy scale correlated negatively with a measure of marital satisfaction, which was also administered to the men (Roach et al., 1979). The AWS and MTFC were weakly associated with each other at pre and post-testing $(r=-0.14$ and -0.21 ). Both of these measures were correlated in expected directions with 
Anger Toward Partner at the post-test but not at the pretest $(r=0.20$ and -0.20 ). The two measures of reactions to women were not related to jealousy or depression. Thus, most of the relationships among the outcome variables were those which were expected based on current theories about anger arousal, in particular as they apply to men who batter. They also suggest that changes in one outcome variable will be associated with changes in certain other ones.

\section{Correlations with Partners' Reports of Violence}

An assessment of the external validity of the self-reports of a sample of the men was attempted by correlating their reports with reports of their violent behavior as given by their partners. Because many women leave their partners after treatment or are difficult to locate and because data were lacking on men in earlier groups, a comparison between the men's selfreports and the women's follow-up reports could only be made for 19 couples. Only two of the outcome measures of this study were available for this analysis because many follow-ups were completed on earlier groups which used a somewhat different measurement package.

The women's post hoc baseline accounts of the violence (at least 1 year) were collected using the Conflict Tactics Scales (Straus, 1979) during an in-person interview before the men began treatment. The same measure was again used in a telephone interview with her at least 6 months after the man completed treatment. If the follow-up and base-line periods were not exactly a year, the frequency of abuse was converted to yearly rates.

The overall change score for all forms of physical abuse on the Conflict Tactics Scale was correlated with change scores of the MTFC Scale and the combined scales of the Anger Inventory. The nonparametric correlation coefficient (Spearman) was $0.47(p<0.025)$ between the reductions shown on the Anger Inventory and reductions in violence reported by the women. The MTFC Scale did not show a significant relationship ( $r=0.10$, NS) with violence reduction.

\section{RESULTS}

Table I shows the pretest and posttest means in two forms, unadjusted and adjusted for social desirability response bias. The Anger Toward Partner Scale showed a significant decrease in the level of extreme forms of anger the men reported they would have in various situations with their partners. This decrease was maintained after controlling for social desirability response bias.

The Anger Toward Work/Friend Relationships Scale also showed a significant change from before to after treatment using both unadjusted 
Table I. Pretreatment and Post-Treatment Means and Standard Deviations

\begin{tabular}{|c|c|c|c|c|c|c|c|}
\hline \multirow[b]{2}{*}{ Measure } & & \multicolumn{3}{|c|}{ Unadjusted } & \multicolumn{3}{|c|}{ Adjusted $^{a}$} \\
\hline & & Pre & Post & $t$ & Pre & Post & $\bar{t}$ \\
\hline $\begin{array}{l}\text { Anger Toward } \\
\text { Partner }^{b}\end{array}$ & $\begin{array}{l}\mathrm{M} \\
\mathrm{SD}\end{array}$ & $\begin{array}{l}27.7 \\
19.0\end{array}$ & $\begin{array}{l}18.9 \\
18.8\end{array}$ & $4.03^{*}$ & $\begin{array}{l}57.9 \\
18.2\end{array}$ & $\begin{array}{l}40.3 \\
18.5\end{array}$ & $7.32 *$ \\
\hline $\begin{array}{l}\text { Anger Toward } \\
\text { Work/Friend }^{b}\end{array}$ & $\begin{array}{r}\mathrm{M} \\
\mathrm{SD}\end{array}$ & $\begin{array}{l}19.2 \\
15.1\end{array}$ & $\begin{array}{l}14.1 \\
13.7\end{array}$ & $3.73^{*}$ & $\begin{array}{l}40.7 \\
13.7\end{array}$ & $\begin{array}{l}28.4 \\
13.4\end{array}$ & $9.11^{*}$ \\
\hline $\begin{array}{l}\text { Male Threat } \\
\text { From Female } \\
\text { Competence }^{c}\end{array}$ & $\begin{array}{l}\mathrm{M} \\
\mathrm{SD}\end{array}$ & $\begin{array}{l}2.1 \\
1.7\end{array}$ & $\begin{array}{l}2.0 \\
1.7\end{array}$ & 0.38 & $\begin{array}{l}4.0 \\
1.6\end{array}$ & $\begin{array}{l}3.3 \\
1.7\end{array}$ & $3.45^{*}$ \\
\hline $\begin{array}{l}\text { Beck } \\
\text { Depression } \\
\text { Inventory }^{d}\end{array}$ & $\begin{array}{l}\mathrm{M} \\
\mathrm{SD}\end{array}$ & $\begin{array}{r}11.2 \\
8.8\end{array}$ & $\begin{array}{l}6.4 \\
8.2\end{array}$ & $5.49^{*}$ & $\begin{array}{r}25.4 \\
8.1\end{array}$ & $\begin{array}{l}8.8 \\
8.2\end{array}$ & $20.54^{*}$ \\
\hline $\begin{array}{l}\text { Attitudes } \\
\text { Toward } \\
\text { Woman }^{e}\end{array}$ & $\begin{array}{l}\mathrm{M} \\
\mathrm{SD}\end{array}$ & $\begin{array}{r}11.8 \\
5.8\end{array}$ & $\begin{array}{r}13.9 \\
5.7\end{array}$ & $-3.91^{*}$ & $\begin{array}{l}8.3 \\
5.8\end{array}$ & $\begin{array}{r}15.2 \\
5.7\end{array}$ & $-12.68^{*}$ \\
\hline $\begin{array}{l}\text { Jealousy } \\
\text { Scale }^{f}\end{array}$ & $\begin{array}{l}\mathrm{M} \\
\mathrm{SD}\end{array}$ & $\begin{array}{r}18.0 \\
8.7\end{array}$ & $\begin{array}{r}14.5 \\
7.1\end{array}$ & $3.91^{*}$ & $\begin{array}{r}24.3 \\
8.6\end{array}$ & $\begin{array}{r}16.7 \\
7.1\end{array}$ & $8.74^{*}$ \\
\hline
\end{tabular}

${ }^{*} p<.001$.

${ }^{a}$ Means and standard deviations were adjusted for social desirability response bias.

${ }^{b}$ High score $=$ more anger.

${ }^{c}$ High score $=$ more threat

${ }^{d}$ High score $=$ more depression.

${ }^{e}$ High score $=$ more liberal attitudes.

${ }^{f}$ High score $=$ more jealousy.

and adjusted scores, although the change was not as great as for the partner situations.

Changes in the combined scales on the anger inventory using all five levels of anger were also analyzed. The unadjusted scores showed a significant decrease which was not as great as the changes in the high anger levels and the decrease was not maintained after controlling for response bias.

The scores on the Beck Depression Inventory (BDI) showed significant decreases in depression over the course of treatment using both unadjusted and adjusted scores. Compared with the Beck et al. (1961) psychiatric sample, on the average the men scored in the "mild" range of depression with unadjusted scores before treatment and the "nondepressed" range after treatment. Using adjusted scores, the average was in the "moderate" range before treatment and the "nondepressed" range after treatment.

The scores on the Attitudes Toward Women Scale (AWS) increased significantly on both adjusted and unadjusted scores, showing a liberalization of views about sex roles. Scores on the MTFC Scale showed no significant decrease in threat from female competence for unadjusted scores but they showed a significant decrease for adjusted scores. 
The Jealousy Scale showed a significant average decline in selfreported jealousy in the relationship. This decline also held for adjusted scores.

For all of the measures there were greater changes for the adjusted scores due to a lower association between the Marlowe-Crowne Scale and the outcome measures at the post-test. Thus, the men showed less defensiveness regarding assessment procedures after treatment.

\section{DISCUSSION}

Measures of anger, depression, attitudes about women, and jealousy showed positive changes following cognitive-behavioral group treatment for wife abuse. Evidence for the generalization of the effects are shown because the men reported that they would have lower anger arousal in work and friend situations as well as situations involving their partners. The concomitant changes in the outcome measures can be explained partly because of the original association among these measures at intake. For example, it is not known if the reductions in the likelihood of anger arousal were the result of interventions for anger arousal or for depression, as these two variables were moderately correlated.

Results of this study indicate that a cognitive-behavioral approach holds promise for treating men who perpetrate wife abuse. Even though changes in abusive behavior were not directly measured, the variables used in the study have been shown to correlate with the presence or frequency of woman abuse, either in this sample or in other studies. Follow-up contacts with $\mathbf{4 5}$ of the partners have been completed, and the results of this followup study will be the subject of a separate report. Briefly, the results showed a significant decrease in the frequency of violent episodes from before to after treatment. In response to an open-ended question about positive change, $68 \%$ of the 34 women whose partners completed treatment and who remained in contact attributed positive change to the treatment. About one half of these women $(\mathbf{4 8 \%})$ reported that their partners showed greater expression of feelings. Of the nine women whose partners dropped from treatment, only one mentioned a positive change in the expression of feelings. Thus, there is some corroborating evidence that one of the goals of treatment - the asserive and responsible expression of feelings - was realized.

Despite the promising results, the study has a number of methodological limitations which lead to some suggestions for further research: 
(1) Because no control or comparison group was used in the study, nontreatment factors could explain the changes which were detected from before to after treatment. While a no-treatment control group would be unethical, a minimal treatment group or a comparison treatment group may be ethically acceptable. There are several comparisons that need to be made. for example, between cognitive-behavioral, self-help, and insight methods, and between individual, couple, and group formats.

(2) The reports of behavior were not obtained from either partner after treatment. The ultimate test of treatment effectiveness will be based on the corroboration obtained on the man's behavior from his partner. Because of the difficulties in obtaining follow-up reports, the next best measure would be a pre-post role-play of anger situations using observational and physiological measures (cf. Novaco, 1976).

The finding that clients biased some of their responses in a socially desirable manner has important implications for clinical practice and for follow-up evaluations. This finding validates what has been noted clinically (Ganley, 1981). Moreover, it stresses the need either to use a method of adjusting scores of self-report measures or to measure behavior, preferably based on the partner's reports. The men not only suppressed their reports of anger, which is generally socially unacceptable, but also suppressed their reports of depression, which is an emotion that is socially unacceptable in men.

One of the issues deserving more attention is that of treatment motivation. There is consistency between this study and others which indicate that those most likely to drop out of treatment early are the less educated, unemployed, and single (Lund et al., 1982; Pirog-Good and Stets-Kealey, 1985). The specification of such drop-out risk factors can be used during the assessment phase to conduct pretreatment motivational programs. One strategy, for example, would be to match low motivated men with former, successfully treated clients who have similar backgrounds who could act as supportive "sponsors" before and during treatment.

In conclusion, even with the methodological limitations of the study, the results are encouraging because they showed that attitudes about women, feelings of anger and jealousy, and the depressive symptoms of a poorly motivated population of abusive men could improve in a relatively short period of time.

\section{REFERENCES}

Adams, D. C., and McCormick, A. J. (1982). Men unlearning violence: A group approach based on the collective model. In Roy, M. (ed.), The Abusive Partner, Van Nostrand, New York. 
Allen, R. D. (1978). An analysis of the impact of two forms of short-term assertive training on aggressive behavior. Diss. Abst. Int. 39(4-A): 2058.

Ball, M. (1977). Issues of violence in family casework. Social Casework 58: 3-12.

Beck, A. T., Ward, C. H., Mendelson, M., Mock, J., and Erbaugh, J. (1961). An inventory for measuring depression. Arch. Gen. Psychiat, 4: 53-63.

Bedrosian, R. C. (1982). Using cognitive and systems intervention in the treatment of marital violence. In Hausen, J. C., and Barnhill, L. R. (eds.), Clinical Approach to Family Violence, Aspen, Rockville, Md.

Bernstein, D. A., and Borkevec, T. D. (1973) Progressive Relaxation Training, Research Press, Champaign, Ill.

Brisson, N. (1982). Helping men who batter women. Public Welfare 29-34.

Cate, R. M., Henton, J. M., Koval, J., Christopher, F. S., and Lloyd, S. (1982). Premarital abuse: A social psychological perspective. J. Family Issues 3(1): 79-90.

Coleman, K. H. (1980). Conjugal violence: What 33 men report. J. Marital Family Ther. 6: 207-213.

Cook, D. R., and Frantz-Cook, A. (1984). A systemic treatment approach to wife battering. J. Marital Family Ther. 10(1): 83-93.

Crowne, D. P., and Marlowe, D. (1964). The Approval Motive: Studies in Evaluative Dependence, Wiley, New York.

Deschner, J. P. (1984). The results of anger control for violent couples. Paper presented at the Second National Conference for Family Violence Researchers, University of New Hampshire.

Edleson, J. F. (1984). Working with men who batter. Social Work 29: 237-242.

Edleson, J. F., Miller, D. M., Stone, G. W., and Chapman, D. G. (1985). Group Treatment for Men Who Batter, Social Work Research and Abstracts, 2l(3): 18-21.

Edleson, J. L., and Brygger, M. P. (1986). Gender differences in reporting of battering incidences. Family Relations 35(3): 377-382.

Edleson, J. L., and Grusznski, R. J. (1986) Treating men who batter: Four years of outcome data from the domestic abuse project. Unpublished manuscript, University of Minnesota School of Social Work.

Frederiksen, L. W., and Rainwater, N. (1981). Explosive behavior: A skill development approach. In Stuart, R. B., (ed.), Violent Behavior: Social Learning Approaches to Prediction, Management and Treatment, Bruner/Mazel, New York.

Foy, D. W., Eisler, R. M., and Pinkston, S. (1975). Modeled assertion in a case of explosive rage. J. Behav. Ther. Exp. Psychiat. 6: 135-137.

Ganley, A. L. (1981). Court-Mandated Counseling for Men Who Batter, Center for Women's Policy Studies, Washington, D.C.

Geller, J. A., and Walsh, J. C. (1977-78). Victimol. Int. J. 2: 627-632 (3-4).

Geller, J. A., and Wasserstrom, J. (1984). Conjoint therapy for the treatment of domestic violence. In Roberts, A. R. (ed.), Battered Women and Their Families, Springer, New York:

Goffman, J. M. (1980). Batterer's Anonymous: Mutual Support Counseling for WomanBatterers, Coalition for the prevention of Abuse of Women and Children, Redlands, Calif.

Greenwald, H. J., and Satow, Y. (1970). A short social desirability scale. Psychol. Rep. 27: 131-135.

Herman, J. L. (1986). Histories of violence in an outpatient population: An exploratory study. Am. J. Orthopsychiat. 56(1): 137-141.

Hilberman, E., and Munson, K. (1977.78). Sixty battered women. Victimology 2(3-4): $460-470$.

Howells, K. (1976). Interpersonal aggression. Int. J. Criminol. Penol. 4: 319-330.

Jouriles, E. N., and O'Leary, K. D. (1985). Interpersonal reliability of reports of marital violence. J. Consult. Clin. Psychol. 53: 419-421.

Kenny, M. A. (1981). Family relationships in domestic violence disturbances. Diss. Abst. Int. 41(8): 3734-A.

Laner, M. R. (1983). Courtship abuse and aggression: Contextual aspects. Sociol. Spect. $3(1): 69-83$. 
Lesser, B. Z. (1981). Factors influencing battered women's return to their mates following a shelter program. Diss. Abst. Int. 42(1): 379-B.

Levine, M. B. (1975). Interparental violence and its effect on children: A study of 50 families in general practice. Med. Sci. Law 5: 172-176.

Lund, S. H., Larsen, N. E., and Schultz, S. K. (1982). Exploratory evaluation of the domestic abuse project. Unpublished manuscript, Program Evaluation Resource Center, Minneapolis.

Makepeace, J. (1981). Courtship violence among college students. Family Relat. 30(1): $97-102$.

Margolin, G. (1979). Conjoint marital therapy to enhance anger management and reduce spouse abuse. Am. J. Family Ther. 7(2): 13-24,

Myers, C. (1984). The family violence project: Some preliminary data on a treatment program for spouse abuse. Paper presented at the Second National Conference for Family Violence Researchers, University of New Hampshire.

Moore, J. G. (1975). The yo-yo syndrome: A matter for interdisciplinary concern. Med. Sci. Law 15: 234-237.

Neidig, P. H., and Friedman, D. H. (1984). Spouse Abuse: A Treatment Program for Couples, Research Press, Champaign, Ill.

Neidig, P. H., Collins, B. S., and Friedman, D. H. (1986). Attitudinal characteristics of males who have engaged in spouse abuse. J. Family Viol. 1: 223-233.

Novaco, R. W. (1976). Anger Control: The Development and Evaluation of an Experimental Treatment, Lexington Books, Lexington, Mass.

Novaco, R. W. (1977). Stress inoculation: A cognitive therapy for anger and its application to a case of depression. J. Consult. Clin. Psychol. 45: 600-608.

Novaco, R. W. (1978). Anger and coping with stress: Cognitive behavioral interventions. In Foreyt, J. P., and Rathjen, D. P. (eds.), Cognitive Behavior Therapy: Research and Applications, Plenum, New York.

Pagelow, M. (1981). Women-battering: Victims and their experiences, Sage, Beverly Hills.

Pirog-Good, M., and Stets-Kealey, J. (1985). Male batterers and battering prevention programs: A national survey. Response Victim. Women Child. 1: 223-233.

Pirog-Good, M., and Stets-Kealy, J. (in press). Recidivism in programs for abusers. Victimol. Int. $J$.

Pleck, J. H. (1982). Male threat from female competence. J. Consult. Clin. Psychol. 44: 608-613.

Rimm, D. C. (1977). Assertiveness training and the expression of anger. In Alberti, R. E. (ed.), Assertiveness: Innovations, Applications, and Issues, Impact, San Luis Obispo, CA.

Roach, A. J., Frazier, L. P., and Bowden, S. R. (1981). The marital satisfaction scale: Development of a measure for intervention research. J. Marriage Family 43: 537-546.

Roberts, A. R. (1982). A national survey of services for batterers. In Roy, M. (ed.), The Abusive Partner, Van Nostrand, New York, pp. 230-243.

Rouse, L. P. (1984). Models of self-esteem and locus of control as factors in spouse abuse. Victimol. Int. J. 9(1): 130-141.

Saunders, D. G. (1977). Marital violence: Dimensions of the problem and modes of intervention. J. Marriage Family Counsel. 3: 43-52.

Saunders, D. G. (1982). Counseling the violent husband. Innovations in Clinical Practice: A Source Book, Vol. 1, Keller, P. A., and Ritt, L. G. (eds.), Professional Resource Exchange, Sarasota, Fla.

Saunders, D. G. (1984). Helping husbands who batter. Social Casework 65(6): 347-352.

Scott, P. D. (1974). Battered wives. Brit. J. Psychiat. 125: 433-441.

Spence, J. T., Helmreich, R. L., and Stapp, J. (1975). Ratings of self and peers on sex role attributes and their relation to self-esteem. J. Personal. Social Psychol. 32: 29-39.

Spence, J. T., and Helmreich, R. L. (1978). Masculinity and Femininity: Their Psychological Dimensions, Correlates and Antecedents, Univ. of Texas, Austin.

Snyder, D. K., and Scheer, N. S. (1981). Predicting disposition following brief residence at a shelter for battered women. J. Commun. Psychol. 9(5): 559-566. 
Stacey, W. A., and Shupe, A. (1984). An evaluation of three programs for abusive men in Texas. Research Monograph No. 29, Division of Family Life, Center for Social Research, The University of Texas at Arlington.

Stark, E., Flitcraft, A., and Frazier, W. (1979). Medicine and patriarchal violence: The social construction of a "private" event. Int. J. Health Serv. 9(3): 461-493.

Straus, M. A. (1979). Measuring Intrafamily conflict and violence: The Conflict Tactics (CT) Scales. J. Marriage Family 41(1): 75-88.

Straus, M. A., Gelles, R. J.., and Steinmetz, S. K. (1980). Behind Closed Doors: Violence in the American Family, Double Day/Anchor, New York.

Turner, C. W., Fenn, M. R., and Cole, A. M. (1981). A social psychological approach to the treatment of abusive families. In Stuart, R. B. (ed.), Violent Behavior: Social Learning Approaches to Prediction, Management and Treatment. Bruner/Mazel, New York.

Rimm, D. C. (1977). Assertive training and the expression of anger. In Alberti, R. E. (ed.), Assertiveness: Innovations, Applications, and Issues, Impact, San Luis, Obispo, Calif.

Rimm, D. C., de Groot, J. C., Boord, P., Reiman, J., and Dillow, P. V. (1971). Systematic desensitization to an anger response. Behav. Res. Ther. 9: 273-280.

Walker, L. E. (1984). The Battered Woman Syndrome, Springer, New York.

Westra, B., and Martin, H. P. (1981). Children of battered women. Maternal Child Nursing $J .10(1)$ : 41-54.

White, G. L. (1977). The social psychology of romantic jealousy. Diss. Abst. Int. 37(10): 5449-B.

Yllo, K. (1983). Sexual equality and violence against wives in American states. J. Comp. Fam. Studies 14(1): 67-86. 